\title{
Genome-wide detection of selection signatures in Chinese indigenous Laiwu pigs revealed candidate genes regulating fat deposition in muscle
}

\author{
Minhui Chen ${ }^{1 \dagger}$, Jiying Wang ${ }^{2 \dagger} \mathbb{D}$, Yanping Wang ${ }^{2}$, Ying $\mathrm{Wu}^{2}$, Jinluan $\mathrm{Fu}^{1 *}$ and Jian-feng $\mathrm{Liu}^{1 *}$
}

\begin{abstract}
Background: Currently, genome-wide scans for positive selection signatures in commercial breed have been investigated. However, few studies have focused on selection footprints of indigenous breeds. Laiwu pig is an invaluable Chinese indigenous pig breed with extremely high proportion of intramuscular fat (IMF), and an excellent model to detect footprint as the result of natural and artificial selection for fat deposition in muscle.

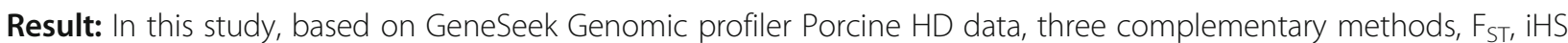
(integrated haplotype homozygosity score) and CLR (composite likelihood ratio), were implemented to detect selection signatures in the whole genome of Laiwu pigs. Totally, 175 candidate selected regions were obtained by at least two of the three methods, which covered $43.75 \mathrm{Mb}$ genomic regions and corresponded to $1.79 \%$ of the genome sequence. Gene annotation of the selected regions revealed a list of functionally important genes for feed intake and fat deposition, reproduction, and immune response. Especially, in accordance to the phenotypic features of Laiwu pigs, among the candidate genes, we identified several genes, NPY1R, NPY5R, PIK3R1 and JAKMIP1, involved in the actions of two sets of neurons, which are central regulators in maintaining the balance between food intake and energy expenditure.

Conclusions: Our results identified a number of regions showing signatures of selection, as well as a list of functionally candidate genes with potential effect on phenotypic traits, especially fat deposition in muscle. Our findings provide insights into the mechanisms of artificial selection of fat deposition and further facilitate follow-up functional studies.
\end{abstract}

Keywords: Selection signatures, Chinese indigenous breed, Fat deposition, Laiwu pigs

\section{Background}

Domestic animals have been subjected to a series of strong artificial selection to meet the demand of humans, such as growth rate, body size, muscle composition and reproduction. These processes of selection have left signatures, such as reduced genetic diversity and long haplotypes, in the genomes of domestic animals. The advent of high-throughput genotyping and

\footnotetext{
*Correspondence: fujinlian@126.com; liujf@cau.edu.cn

${ }^{\dagger}$ Equal contributors

${ }^{1}$ Key Laboratory of Animal Genetics, Breeding and Reproduction, Ministry of Agriculture, College of Animal Science and Technology, China Agricultural University, Beijing 100193, China

Full list of author information is available at the end of the article
}

sequencing techniques has facilitated the detection of selection signatures in domestic animals at the genome level. Recent studies have identified candidate genes with distinct patterns of differentiation underlying the phenotypic diversity of breeds, for example, KIT and MC1R genes were related with a series of pig breed color types [1], NR6A1, PLAG1 and LCORL genes are associated with an increased number of vertebrae and an elongation of the animal's back [1]; GHRL gene was a candidate for associations with appetite and feeding behavior [2].

So far, various analytic methods have been proposed to detect different kinds of selection signatures, such as $\mathrm{F}_{\mathrm{ST}}$ [3], extended haplotype homozygosity (EHH) [4], iHS

(c) The Author(s). 2018 Open Access This article is distributed under the terms of the Creative Commons Attribution 4.0 International License (http://creativecommons.org/licenses/by/4.0/), which permits unrestricted use, distribution, and reproduction in any medium, provided you give appropriate credit to the original author(s) and the source, provide a link to the Creative Commons license, and indicate if changes were made. The Creative Commons Public Domain Dedication waiver (http://creativecommons.org/publicdomain/zero/1.0/) applies to the data made available in this article, unless otherwise stated. 
(integrated haplotype homozygosity score) [5] and CLR (composite likelihood ratio) [6]. Based on these methods, genome-wide scans for signatures of diversifying selection have been successfully applied to domestic animals [7-9]. Additionally, in most cases, more than a single method is necessary in order to map the comprehensive footprint of selection in the genome. On the other hand, combining multiple methods into composite tests can lead to greater power and spatial resolution [10]. A good example is the CMS (composite of multiple signals) method [11], which combines iHS, XP-EHH (cross population extended haplotype homozygosity), $\mathrm{F}_{\mathrm{ST}}$, $\triangle \mathrm{DAF}$ and $\triangle \mathrm{iHH}$.

Laiwu pig is an invaluable Chinese indigenous pig breed, and distributed mainly in Laiwu district, Shandong province of China. Laiwu pig has been well-known for its high proportion of intramuscular fat (IMF) [12-14]. The unique breed feature of Laiwu pigs has come about as a result of natural and artificial selection. Therefore, it serves as an excellent model to detect footprint of selection for fat deposition in muscle, which would be beneficial for the identification of porcine genes related to IMF deposition as well as for better understanding the genetic basis of high IMF. Therefore, in this study, we investigated genomic regions under selection in Laiwu pigs using three integrative methods, $\mathrm{F}_{\mathrm{ST}}$, iHS and CLR, based on genomewide SNP genotyping data from Laiwu and Yorkshire pigs. Furthermore, in order to achieve greater power, regions identified by multiple methods were considered as candidate selected regions. Distinct patterns of selection signatures were found at loci that may contribute to domestication phenotypes, especially IMF.

\section{Methods}

\section{Sample preparation and whole genome SNP genotyping}

Fifty Laiwu pigs and 52 Yorkshire pigs were randomly selected from Laiwu pig conservation farm and one Yorkshire breeding farm, respectively, and genomic DNA of these samples were extracted from their ear tissues using a standard phenol/chloroform method. Both Laiwu and Yorkshire pigs belonged to one company, and used the same feeding condition except that Laiwu pigs had lower protein and higher fiber levels than Yorkshire. Genotyping was performed using GeneSeek Genomic Profiler Porcine HD BeadChip (Neogen Corporation, USA) according to the manufacturer's instructions.

To ensure the high quality of the data, we performed the following criteria for quality control using PLINK (v1.07) [15]: (i) individuals with low genotype call rate $(<95 \%)$ were removed; SNPs were removed (ii) when the SNPs were fixed in both populations, (iii) when there were no known autosomal genomic locations in Sus scrofa build 10.2 [16].
Closely related individuals in the samples could bias the estimations of allele frequencies and haplotype frequencies, and thus it might mask the signature of selection. So, relatedness tests within each population were performed to ensure independence among individuals using another dataset generated by the following data filtering. Firstly, we excluded SNPs with minor allele frequency $(\mathrm{MAF})<0.05$. Then, to reduce the dependency of SNPs in the relatedness test, we generated a pruned dataset with SNPs in approximate linkage equilibrium using the option of -indep-pairwise 5050.5 in PLINK (v1.07) [15]. This option removed one of each pair of SNPs with a pairwise $r^{2}>0.5$ within a window of 50 SNPs, and shifted the window by a step size of 5 SNPs. We used GCTA (V 1.26.0) [17] to compute the genetic relationship matrix [18] and removed one individual from each pair with genetic relationship higher than 0.2 .

\section{Detection of selection signatures between Laiwu and Yorkshire}

We implemented a Bayesian method [19] to estimate $\mathrm{F}_{\mathrm{ST}}$ statistics between Laiwu and Yorkshire. This method assigns a weakly informative prior distribution $\left(\operatorname{Beta}\left(\frac{1}{2}, \frac{1}{2}\right.\right.$ )) of allele frequencies. Thus, allele frequencies follow a posterior beta distribution with parameters $\alpha=n_{A}+\frac{1}{2}$ and $\beta=n_{a}+\frac{1}{2}$, here $\mathrm{n}_{\mathrm{A}}$ and $\mathrm{n}_{\mathrm{a}}$ indicate the counts of allele $\mathrm{A}$ and $\mathrm{a}$ in the population. The posterior distribution of allele frequencies is then used to produce the posterior distribution of $\mathrm{F}_{\mathrm{ST}}$. Let $p_{r, l}^{(s)}(s=1,2, \cdots, S)$ be one sample from the posterior distribution of $p_{r, l}$, the frequency of allele $\mathrm{A}_{l}$ at locus $l$ in population $\mathrm{r}(r=1,2$, $\cdots R$ ). Then, a draw from the posterior distribution of $\mathrm{F}_{\mathrm{ST}}$ is given by:

$$
F_{S T 1}^{(\mathrm{s})}=\frac{\sum_{\mathrm{r}=1}^{\mathrm{R}}\left(\mathrm{p}_{\mathrm{r}, 1}^{(\mathrm{s})}\right)^{2}-\frac{\left(\sum_{\mathrm{r}=1}^{\mathrm{R}} \mathrm{p}_{\mathrm{r}, 1}^{(\mathrm{s})}\right)^{2}}{\mathrm{R}}}{\left(\frac{\mathrm{R} \sum_{\mathrm{r}=1}^{\mathrm{R}} \mathrm{p}_{\mathrm{r}, 1}^{(\mathrm{s})}-\left(\sum_{\mathrm{r}=1}^{\mathrm{R}} \mathrm{p}_{\mathrm{r}, 1}^{(\mathrm{s})}\right)^{2}}{\mathrm{R}}\right)}
$$

From $\mathrm{S}$ samples of $\mathrm{F}_{\mathrm{ST}}$ values, the mean of the posterior distribution of $\mathrm{F}_{\mathrm{ST}}$ can be calculated and taken as the point estimate of $\mathrm{F}_{\mathrm{ST}}$.

To identify highly differentiated regions, we divided the genome into $500-\mathrm{kb}$ windows with a $250-\mathrm{kb}$ overlap. The averaged $\mathrm{F}_{\mathrm{ST}}$ value was calculated across the SNPs located within each window and was used as the test statistic. Windows falling in the top 5\% of the empirical distribution were considered to be candidate regions under positive selection. 
Detection of selection signatures within Laiwu pigs

We also conducted two analytic methods, iHS and CLR tests, within Laiwu pigs. In both tests, we used the ancestral and derived alleles at each SNP locus from a previous study [20], which were determined by using four Sus species (Sus barbatus, Sus celebensis, Sus verrucosus and Sus cebifrons) and one Phacochoerus species (African warthog) as outgroups.

For iHS test, we imputed missing genotypes and inferred haplotype phase using BEAGLE (version 3.3.2) [21]. The iHS statistics were then calculated for all SNPs with MAF higher than $5 \%$, using the software package coded by Voight and Kudaravalli [5]. This statistic compares the extent of LD between haplotypes carrying the ancestral allele and haplotypes carrying the derived allele. It integrates the $\mathrm{EHH}$ away from a specified core allele until EHH reaches 0.05. The integrated $\mathrm{EHH}(\mathrm{iHH})$ is denoted as $\mathrm{iHHA}$ or $\mathrm{iHHD}$, depending on whether the core allele is ancestral or derived. The unstandardized integrated haplotype score (iHS) is defined as

$$
\text { unstandardized } i H S=\ln \left(\frac{i H H_{A}}{i H H_{D}}\right)
$$

In the neutral model, for SNPs with comparable derived allele frequency, unstandardized his values are approximately normally distributed [5]. Thus, we split unstandardized iHS into 20 equally-sized derived allele frequency bins, i.e., with derived allele frequencies ranging from 0 to $5 \%, 5$ to $10 \%$, and so on. The unstandardized iHS were then normalized in each bin to obtain a zero mean and unit variance. Therefore, a large positive or negative value of iHS indicates that haplotypes carrying the ancestral or derived allele present unusually high haplotype homozygosity. To define candidate regions, we divided the genome into $500-\mathrm{kb}$ windows with a 250 $\mathrm{kb}$ overlap and used the averaged $|\mathrm{iHS}|$ value in each window as the test statistic. Windows at the top 5\% of the empirical distribution were considered to be candidate regions of positive selection.

A recent selective sweep causes a skew of frequency spectrum at linked sites, such as reduced genetic diversity and an excess of derived alleles at high frequencies $[22,23]$. CLR test compares a neutral model for allele frequency spectrum with a selective sweep model. In the neutral model, the probability of allele frequency spectrum is derived from the background pattern of variation in the genome. We used SweepFinder2 [24] to calculate the CLR statistics for sites every $20 \mathrm{~kb}$ across the genome. To define candidate region, we divided the genome into $500-\mathrm{kb}$ windows with a $250-\mathrm{kb}$ overlap. In each window, the maximum CLR was used as the test statistic, following a previous approach [25]. Windows at the top 5\% of the empirical distribution were considered to be candidate regions of positive selection.

To further control the false positive rates of the detection of selection signatures, genomic regions identified by at least two methods were used in further analyses.

\section{Functional characterization of genomic regions under selection}

Gene contents in candidate selected regions were retrieved from Ensembl Genes 89 Database using BioMart (http://asia.ensembl.org/biomart/martview/). QTLs (quantitative trait loci) were downloaded from the Pig QTLdb (http://www.animalgenome.org/cgi-bin/QTLdb/SS/download?file=bedSS_10.2), and compared with those selected regions based on the putative location of the QTLs. Furthermore, bioinformatics analyses including Gene Ontology (GO) and KEGG pathway enrichment analyses were performed using DAVID 6.8 (https://david.ncifcrf. gov/\#, Oct. 2016) to reveal the potential biological function of candidate genes harbored in selected regions. The enriched GO terms and pathways with $P$-values $<0.05$ were used for further analysis in our study.

\section{Results}

\section{Information of chip data}

A total of 68,516 SNPs were genotyped by GeneSeek Genomic Profiler Porcine HD BeadChip. After a series of quality control, 50,432 autosomal SNPs were remained for the 50 Laiwu pigs and 52 Yorkshire pigs. The average distance between adjacent SNPs was 51 . $4 \mathrm{~kb}$, with the standard deviation of $79.7 \mathrm{~kb}$. Therefore, we chose a window size of $500 \mathrm{~kb}$ to identify candidate region so that on average there were about 10 SNPs in per window.

In the process of relatedness test to ensure no common ancestry for 3 generations among sample used in selection signatures detection, 35 Laiwu pigs and 26 Yorkshire pigs were excluded because of their close relationships (genetic relationship higher than 0.2 ). The genetic relationships between individuals before and after removing these closely individuals are shown in Additional file 1: Figure S1. Finally, 15 Laiwu pigs and 26 Yorkshire pigs were left for the detection of selection signatures. These samples sizes were sufficient to estimate allele frequencies, based on which $\mathrm{F}_{\mathrm{ST}}$ and CLR were calculated. Taking account for the small effective population sizes in pig breeds, the sample sizes should also be sufficient for iHS in comparison with human populations, where 40 chromosomes could provide moderate power in iHS test in Yoruba in Ibadan, Nigeria [25].

\section{Genome-wide scanning for selection signatures}

To detect signatures of positive selection in Laiwu pigs, we used three statistical analysis methods. We first used 
$\mathrm{F}_{\mathrm{ST}}$ statistic to make comparisons between Laiwu pigs and Yorkshire. $\mathrm{F}_{\mathrm{ST}}$ values for SNPs ranged from 0.006 to 0.952 , with an average of 0.169 and standard deviation of 0.167 . The genome-wide distribution of the averaged $\mathrm{F}_{\mathrm{ST}}$ for 500-kb window is shown in Fig. 1. A total of 486 candidate windows (Additional file 2: Table S1), falling in the top $5 \%$ of the empirical distribution, were considered to be candidate regions under positive selection. Additionally, among these candidate windows, there were two clusters with extremely high differentiation. The first cluster was on Sus scrofa chromosome 1 (SSC1), with the window 165.00-166.00 Mb presenting $\mathrm{F}_{\mathrm{ST}}$ value of 0.83 . The second cluster was on SSC8, with the window $46.50-47.00 \mathrm{Mb}$ presenting the highest $\mathrm{F}_{\mathrm{ST}}$ value of 0.95 .

We also ran two within-population methods, iHS and CLR, to detect selection signatures within Laiwu pig population. Figure 2 shows the genome-wide distribution of iHS values. The genome-wide mean $|\mathrm{iHS}|$ value was 0.43 , and the highest average $|\mathrm{iHS}|$ value was 3.48 for the window on SSC15 (spanning 134.25-134.75 Mb). There were 480 windows (Additional file 3: Table S2) at the top $5 \%$ of the empirical distribution that were considered to be candidate regions of positive selection. Figure 3 illustrates the CLR statistic against the genomic position for Laiwu pigs. The result provided strong evidence of a selective sweep on SSC8, with a cluster of extreme signals and two windows $(54.50-55.00 \mathrm{Mb}$ and 54 . $75-55.25 \mathrm{Mb}$ ) harboring the largest CLR value (88.09). Across the genome, we observed 490 windows (Additional file 4: Table S3) with extreme CLR values that were considered candidate regions of positive selection.

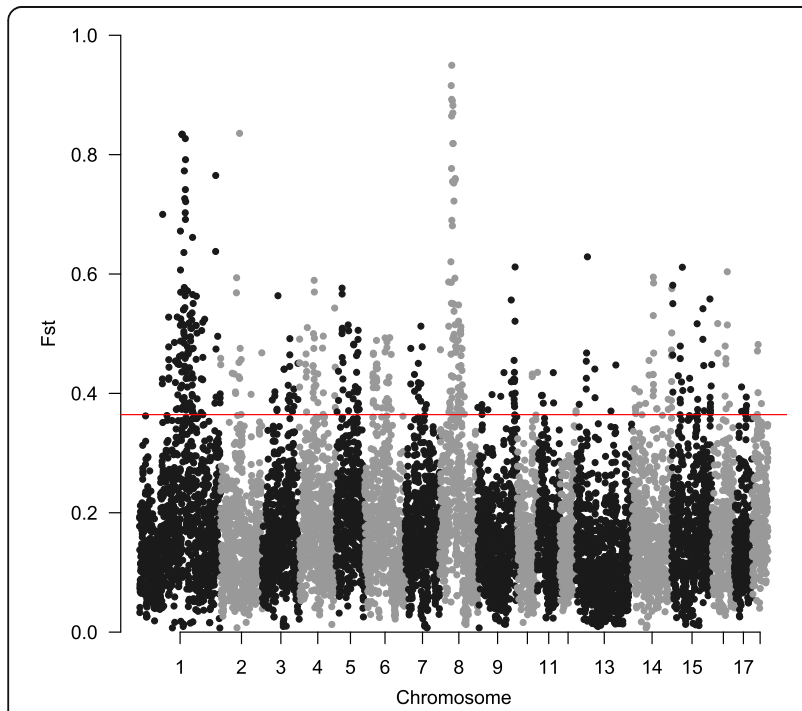

Fig. 1 Genome-wide distribution of selection signatures detected by $\mathrm{F}_{\mathrm{ST}}$ on 18 chromosomes. Red line displays the threshold levels of 5\%

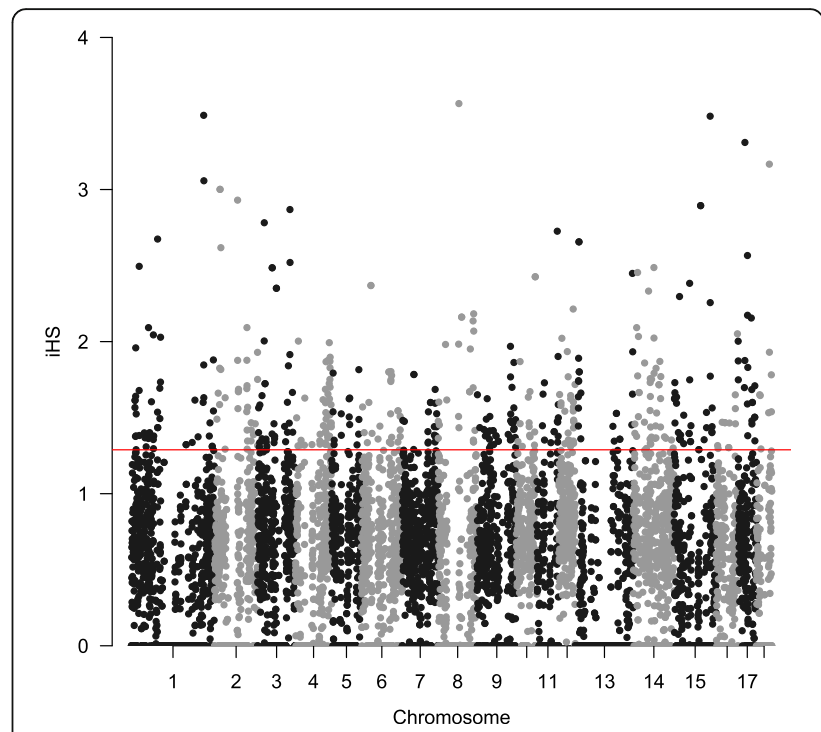

Fig. 2 Genome-wide distribution of selection signatures detected by iHS on 18 chromosomes. Red line displays the threshold levels of $5 \%$

\section{Overall comparison of selection signatures between methods}

The distribution of overall candidate selected regions along the genome has been shown in Fig. 4. Genomic regions identified by at least one method covered $465 \mathrm{Mb}$. Among them, the candidate regions obtained by both $\mathrm{F}_{\mathrm{ST}}$ and CLR covered $29.75 \mathrm{Mb}$; the candidate regions obtained by both $\mathrm{F}_{\mathrm{ST}}$ and iHS covered $9 \mathrm{Mb}$; the candidate regions obtained by both CLR and iHS covered 5 . $5 \mathrm{Mb}$. Besides, there was one region 2.75-3.0 Mb on SSC8 identified by all three methods.

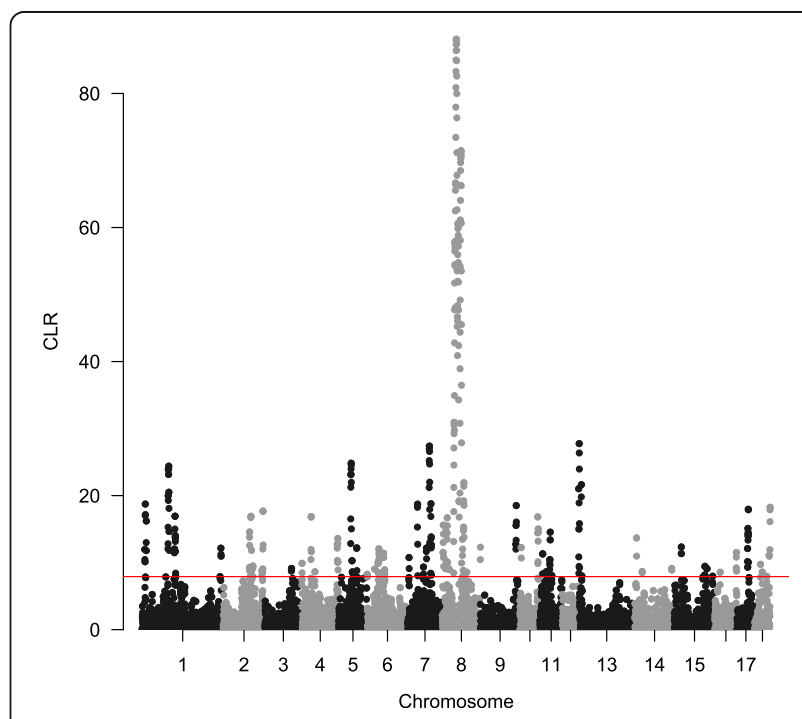

Fig. 3 Genome-wide distribution of selection signatures detected by CLR on 18 chromosomes. Red line displays the threshold levels of 5\% 


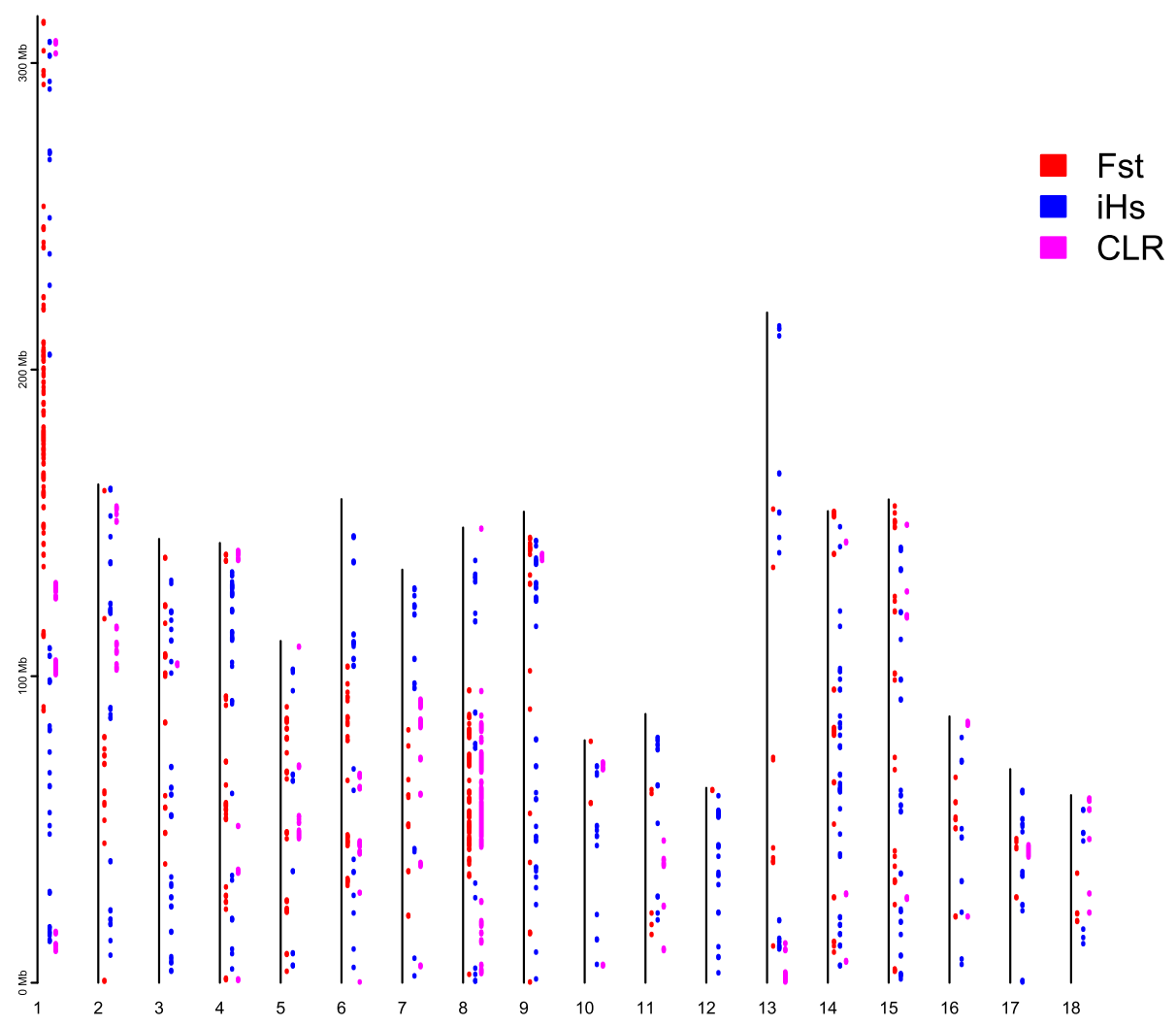

Fig. 4 Genomic distribution of selection signatures detected by $F_{S T}$, iHS and CLR on 18 chromosomes

In order to decrease the false positive regions identified, candidate regions obtained by at least two of the three methods were considered to be final candidate regions of positive selection. Totally, there were 175 candidate regions (Additional file 5: Table S4) obtained by at least two of the three methods, covering $43.75 \mathrm{Mb}$ genomic regions and corresponding to $1.79 \%$ of the autosome sequence. The numbers of candidate selected regions are uneven distributed across the genome. The biggest number of regions were observed on SSC8 (86 regions), while no ones were found on SSC12.

\section{Functional characterization of candidate regions}

Totally, 438 genes within the identified selected regions were retrieved from Ensembl Genes 89 Database, including 395 protein-coding genes, seven miRNA, three pseudogenes, nine snoRNA, 16 snRNA, three rRNA, and four miscRNA (Additional file 6: Table S5). We noted that some selected regions were mapped in the gene desert, which accounted for approximately $25.14 \%$ of all selected regions, indicating the important function of non-coding sequence in the selection process. Though some genes are yet not annotated, gene annotation of selected regions revealed a list of functionally important genes, such as NPY1R, NPY5R, PIK3R1 and JAKMIP1 for feed intake and fat deposition, ESR1 and PTHLH for reproduction, and CXCL2, CXCL8 and TLR2 for immune response. Table 1 summarizes ten candidate selected regions harboring interesting genes.

We further investigated the functions associated with the annotated genes undergoing positive selection by analyzing over-represented $\mathrm{GO}$ terms and pathways using DAVID. The significant enriched GO terms and KEGG pathways are shown in Additional file 7: Table S6. A total of 34 significant enriched GO terms with $P$-value $<0.05$ were observed, including 16 terms for functional terms (BP) category, 12 terms for molecular function (MF) category, and five terms for cellular component (CC) category. For BP category, most of the terms were involved in regulation of basic metabolic process, cell proliferation, signaling pathway, such as regulation of cell proliferation (0042127), epidermal growth factor receptor signaling pathway (GO:0007173), neuropeptide signaling pathway (0007218). Besides, some of these significant enriched terms were involved in feed behavior and immune response. The 10 most important enriched functional BP terms are summarized in Table 2.

In addition, there were 18 significant pathways enriched (Additional file 8: Table S7), such as steroid hormone biosynthesis (ssc00140), metabolic pathways (ssc01100), chemokine signaling pathway (ssc04062) and salivary secretion (ssc04970). 
Table 1 Summary of the 10 selected regions harboring interesting candidate genes

\begin{tabular}{|c|c|c|c|c|}
\hline SSC & Position (Mb) & Methods & $\begin{array}{l}\text { Candidate } \\
\text { genes }\end{array}$ & Function \\
\hline 1 & $16.50-16.75$ & $\mathrm{iHS}, \mathrm{CLR}$ & ESR1 & Litter size \\
\hline 5 & $49.00-49.25$ & $\mathrm{~F}_{\mathrm{ST},} \mathrm{CLR}$ & PTHLH & $\begin{array}{l}\text { Mammary gland and } \\
\text { nipple development }\end{array}$ \\
\hline 6 & $45.00-45.25$ & $\mathrm{~F}_{\mathrm{ST}}, \mathrm{CLR}$ & TGFB1 & Fat deposition \\
\hline 6 & $45.50-45.75$ & $\mathrm{~F}_{\mathrm{ST}}, \mathrm{CLR}$ & GSK3A & glycogen synthase \\
\hline 8 & $45.25-45.5$ & $\mathrm{~F}_{\mathrm{ST}}, \mathrm{CLR}$ & $C P E$ & Fat deposition \\
\hline 8 & $2.75-3.00$ & $\mathrm{~F}_{\mathrm{ST}}, \mathrm{iHS}, \mathrm{CLR}$ & JAKMIP1 & Feed intake \\
\hline 8 & $55.25-55.50$ & $\mathrm{~F}_{\mathrm{ST}}, \mathrm{CLR}$ & NPY1R, NPY5R & $\begin{array}{l}\text { Stimulation of } \\
\text { appetite }\end{array}$ \\
\hline 8 & $74.00-74.25$ & $\mathrm{~F}_{\mathrm{ST}}, \mathrm{CLR}$ & CXCL2, CXCL8 & Immune response \\
\hline 8 & $79.75-80.00$ & $\mathrm{~F}_{\mathrm{ST}}, \mathrm{CLR}$ & $T L R 2$ & Immune response \\
\hline 16 & $50.25-50.50$ & $\mathrm{~F}_{\mathrm{ST}}, \mathrm{iHS}$ & PIK3R1 & Energy balance \\
\hline
\end{tabular}

\section{Identifying QTL overlapping with candidate selected regions}

We downloaded 16,516 QTLs from the pig QTL database (Release 31, Dec 30, 2016) and identified any overlapping of the candidate selected regions with those QTLs. Consequently, 1519 porcine QTLs (Additional file 9: Table S8) were detected to be overlapped with the candidate selected regions identified. Interestingly, we found that the number of QTLs relating to meat and carcass traits was especially greater than others, with a proportion of 52 . $92 \%$, indicating that selection for meat quality during Laiwu pigs breeding has left a detectable footprint in the pig genome.

Table 2 Summary of 10 enriched functional biological process (BP) terms relevant to phenotypic traits

\begin{tabular}{llll}
\hline Term & Count & $P$-value & Fold enrichment \\
\hline $\begin{array}{l}\text { GO:0070098 chemokine-mediated } \\
\text { signaling pathway }\end{array}$ & 6 & 0.0002 & 10.59 \\
$\begin{array}{l}\text { GO:0007173 epidermal growth factor } \\
\text { receptor signaling pathway }\end{array}$ & 4 & 0.0077 & 9.68 \\
$\begin{array}{l}\text { GO:0042127 regulation of cell } \\
\text { proliferation }\end{array}$ & 7 & 0.0096 & 3.84 \\
$\begin{array}{l}\text { GO:0007218 neuropeptide signaling } \\
\text { pathway }\end{array}$ & 5 & 0.0123 & 5.54 \\
$\begin{array}{l}\text { GO:0002690 positive regulation of } \\
\text { leukocyte chemotaxis }\end{array}$ & 3 & 0.0161 & 15.08 \\
$\begin{array}{l}\text { GO:0050714 positive regulation of } \\
\text { protein secretion }\end{array}$ & 3 & 0.0212 & 13.07 \\
$\begin{array}{l}\text { GO:0032496 response to } \\
\text { lipopolysaccharide }\end{array}$ & 5 & 0.0250 & 4.47 \\
$\begin{array}{l}\text { GO:0033138 positive regulation of } \\
\text { peptidyl-serine phosphorylation }\end{array}$ & 4 & 0.0258 & 6.22 \\
$\begin{array}{l}\text { GO:0097466 glycoprotein ERAD } \\
\text { pathway }\end{array}$ & 2 & 0.0450 & 43.56 \\
GO:0007631 feeding behavior & 3 & 0.0473 & 8.52 \\
\hline
\end{tabular}

\section{Discussion}

In this study, we implemented tests to detect the genome-wide footprints left by natural and artificial selection in Laiwu pigs. Our results revealed a number of regions showing signatures of positive selection. Functional analyses on candidate selected regions supported that these regions had been under selection for fat deposition and the regulation of energy balance. Furthermore, we also found evidence for selection on other traits, such as reproduction and immune response.

With the molecular tools developed for pigs as well as other livestock species, a variety of methods have been developed for detecting different kinds of selection signatures. According to the information used in the test, these methods can be grouped into three categories: population differentiation, site-frequency spectrum and linkage disequilibrium [26, 27]. All the methods detect candidates of different types of selection, and are essential to construct a comprehensive selection map for the pig genome. Therefore, in the present study, we implemented three complementary methods $\left(\mathrm{F}_{\mathrm{ST}}\right.$, iHS and CLR) to comprehensively identify candidate regions of positive selection. As shown in Figs. 1, 2 and 3, different selected regions were obtained by these methods. Comparatively speaking, $\mathrm{F}_{\mathrm{ST}}$ and CLR have the highest overlap rate, with overlapped selected regions of $29.75 \mathrm{Mb}$, whereas $\mathrm{F}_{\mathrm{ST}}$ and iHS, and CLR and iHS only have overlapped selected regions of $9 \mathrm{Mb}$ and $5.5 \mathrm{Mb}$, respectively. However, there was only $0.25 \mathrm{Mb}(2.75-3.0 \mathrm{Mb}$ on SSC8) identified by all the three methods. It is possible that different methods emphasize different information in the data and are sensitive to different categories of selection signatures. Specifically, $\mathrm{F}_{\mathrm{ST}}$ is more powerful for detecting complex events, such as selection on standing variation [28]; iHS test has advantages in exploring selective sweeps with variants at moderate frequencies [29]; and, CLR test is more sensitive to selective sweeps with variants approaching fixation in the population [30]. It is worthy to note that the ascertainment bias in genotyping data might distort the genome-wide distribution of allele frequencies, as well as the estimations of $F_{\mathrm{ST}}$ and CLR. The effect of ascertainment bias can be mitigated by correcting the allelic distribution using statistical methods [6, $31,32]$. However, these methods are not suitable for our study. The GeneSeek Porcine HD BeadChip used in this study was designed mainly using SNPs identified in wild boars and European breeds (https://support.illumina.com. $\mathrm{cn}$ /downloads/geneseek-ggp-porcine-hd-product-files.

html). Since Chinese pigs and European pigs split over 1.2 million years ago [33], these two populations are highly differentiated, as also shown in previous studies [16, 34]. Therefore, the ascertainment scheme in the design of the SNP chip cannot help correct the ascertainment bias effect on Laiwu pigs, a Chinese indigenous breed. 
In comparison with previous genome-wide scans for selection signatures in Chinese indigenous pigs, we find a number of overlapping signatures between Laiwu and other Chinese breeds. Take the cluster of signals detected by both $\mathrm{F}_{\mathrm{ST}}$ and CLR on SSC8 for example, previous analysis [35] in Tongcheng pigs, another typical Chinese indigenous breed, found a series of windows in this region with very low genetic diversity and being highly differentiated from Chinese wild boars, indicative of a selective sweep. Another study on Chinese Rongchang pigs also identified a cluster of selection signatures in this region [36]. Except for this region, we also find clusters of overlapping selection signatures between Laiwu and Tongcheng or Rongchang on other chromosomes, such as the cluster of $\mathrm{F}_{\mathrm{ST}}$ signals on 148.25-149.75 Mb of SSC1.

The primary goal of this study is to identify putative candidate genes involved in Laiwu pigs, which is an invaluable Chinese typical indigenous pig breed with extremely high proportion of IMF. In accordance with the characteristics of Laiwu pigs, a series of genes relevant to phenotypic traits, especially ones regulating feed intake and fat deposition, were annotated in the candidate regions of positive selection, such as NPY1R, NPY5R, PIK3R1 and JAKMIP1. Additionally, some of these functional genes were also detected as being under selection or related with energy balance by previous studies.

The arcuate nucleus of hypothalamus has two sets of neurons, which are two central regulators in maintaining the balance between food intake and energy expenditure [37]. One set of neurons produce agouti-related protein (AGRP) and neuropeptide Y (NPY); another set of neurons produce pro-opiomelanocortin (POMC) and cocaine- and amphetamine-related transcript (CART). The NPY and AGRP are orexigenic, promoting food intake and reducing energy expenditure, while the POMC and CART produce the opposite anorexigenic effect [38]. In this study, we identified a list of genes involved in the actions of these two sets of neurons.

In the cluster of signals identified by both FST and CLR, we identified the NPY1R and NPY5R genes on 55. 25-55.50 Mb of SSC8, which were two receptors of NPY. Previous study showed that the NPY1R and $N P Y 5 R$ appeared to be candidates for mediating the orexigenic effects of NPY [39]. NPY1R and NPY5R double knockout mice behaved as hypophagic, although their body weight increased due to decreased energy expenditure [40]. Genetic association analyses also revealed that these two genes were related to food intake [41] and obesity $[42,43]$ in humans. The signals of selection on the NPY1R and NPY5R genes have also been found in multiple Chinese pig breeds, such as Tongcheng [35], Rongchang and Jinhua [44].

Peripheral endocrine signals, including leptin and insulin, can regulate the energy balance by modulating the activity of arcuate POMC/CART and NPY/AGRP neurons [37]. One part of the effect of leptin and insulin on arcuate neurons was via the activation of phosphoinositide-3-kinase (PI3K) signaling [45-47]. FST and iHS identified signals of selection on the PIK3R1 gene, which encoded three regulatory units of PI3K, including p $85 \alpha, \mathrm{p} 50 \alpha$ and $\mathrm{p} 55 \alpha$. Previous studies $[47,48]$ showed that they played important roles in leptin- and insulin-induced regulation of energy homeostasis.

The NPY/AGRP neurons also have an inhibitory effect on the POMC/CART neurons through the release of GABA [37]. JAKMIP1 is a RNA-binding protein associated with GABAB receptors [49], one of two classes of GABA receptors. It can regulate the cellular levels of GABAB R2 subunits, and may have effects on the production of GABAB receptors [49]. Therefore, the $J A K M I P 1$ gene has a potential effect on the regulation of energy balance. Previous genome-wide association study on residual feed intake in quality chickens found that the polymorphism in the intron of JAKMIP1 gene explained $9.71 \%$ of phenotypic variance [50].

High litter size and good maternity performance were other specific features of Laiwu pigs. Gene annotation on candidate regions also resulted in some genes associated with reproduction traits. For instance, both CLR and iHS identified selection signals of ESR1 gene on SSC1. Estrogen is known for its role in pregnancy. The primary mechanism of its action is mediated through its receptors, i.e., ESR1 and ESR2. Association studies [51-53] have proven the effect of ESR1 on litter size in pigs. Besides, FST and CLR identified the PTHLH gene in the cluster of signals on SSC5. This gene is essential for mammary gland development during embryogenesis [54] and nipple development during pregnancy and lactation [55]. Signals of selection on this gene have also been identified in European pig breeds [2] and Chinese Rongchang pigs [36]. A previous study [56] found that this gene was significantly related to teat number and inverted teat phenotype.

\section{Conclusion}

In summary, we report here the identification of selection signatures in the genome of Laiwu pigs, a typical Chinese indigenous breed. The evidence presented here demonstrates that Laiwu pigs have been under strong selection on fat deposition. Besides, genomic regions under selection also contribute to reproduction and health traits. These results provide insight into the genome evolution and selection mechanisms in Chinese indigenous pig breeds.

\section{Additional files}

Additional file 1: Figure S1. Genetic relationships between individuals before and after removing closely related individuals. (A) genetic relationship in Laiwu pigs before removing closely related individuals; (B) 
genetic relationship in Laiwu pigs after removing closely related individuals; (C) genetic relationship in Yorkshire before removing closely related individuals; (D) genetic relationship in Yorkshire after removing closely related individuals. (PDF $15 \mathrm{~kb}$ )

Additional file 2: Table S1. Summary of selected regions under positive selection detected by FST. (XLSX 51 kb)

Additional file 3: Table S2. Summary of selected regions under positive selection detected by iHS (XLSX $47 \mathrm{~kb}$ )

Additional file 4: Table S3. Summary of selected regions under positive selection detected by CLR. (XLSX $23 \mathrm{~kb}$ )

Additional file 5: Table S4. Summary of overlapping candidate regions under positive selection detected by at least two of the three methods $\mathrm{F}_{\mathrm{ST}}$, iHS and CLR. (XLSX $\left.16 \mathrm{~kb}\right)$

Additional file 6: Table S5. Gene contents in candidate regions under positive selection. (XLSX $38 \mathrm{~kb}$ )

Additional file 7: Table S6. Significantly enriched Gene Ontology terms of candidate genes. (XLSX $12 \mathrm{~kb}$ )

Additional file 8: Table S7. Significantly enriched pathway of candidate genes. (XLSX $10 \mathrm{~kb}$ )

Additional file 9: Table S8. Summary of QTL overlapped with candidate selected regions. (XLSX $150 \mathrm{~kb}$ )

Additional file 10: The ped PLINK file of SNP genotyping data for the 50 Laiwu pigs and 52 Yorkshire pigs. (TXT $21549 \mathrm{~kb}$ )

Additional file 11: The map PLINK file of SNP genotyping data for the 50 Laiwu pigs and 52 Yorkshire pigs. (TXT $1544 \mathrm{~kb}$ )

\section{Abbreviations}

CLR: Composite likelihood ratio; EHH: Extended haplotype homozygosity; GO: Gene ontology; iHS: Integrated haplotype homozygosity score; IMF: Intramuscular fat; LD: Linkage disequilibrium; MAF: Minor allele frequency; SSC: Sus scrofa chromosome

\section{Acknowledgements}

We are grateful to the staff of the Laiwu pig conservation farm for providing ear tissues of Laiwu pigs.

\section{Funding}

Sample preparation and SNP genotyping were supported by grants from the 863 State High-tech Development Plan (2013AA102503), National Natural Science Foundations of China (31372293), and Shandong Swine Industry Technology System Innovation (SDAIT-08-03). Analysis and interpretation of data and the Natural Science Foundations of Shandong Province of China (ZR2017MC043) and Agricultural Science and Technology Innovation Project of SAAS (CXGC2016A04).

\section{Availability of data and materials}

The authors state that all data necessary for confirming the conclusions presented in the article are represented fully within the article. The PLINK files of SNP genotyping data for the 50 Laiwu pigs and 52 Yorkshire pigs are given in Additional files 10 and 11 .

\section{Authors' contributions}

JFL and JF conceived and designed the experiments. MC and JW carried out computational analysis and wrote the manuscript. JFL, YaW and YiW contributed to the sample collecting, DNA extraction, genotyping, and interpretation of data. All authors read and approved the final manuscript.

\section{Ethics approval and consent to participate}

The animals used in this study were raised at Laiwu pig conservation farm and one Yorkshire breeding farm. Ear tissues of the pigs used in the study were collected in strict accordance with guideline (IACC20060101, 1 January 2006), which was approved by the Institutional Animal Care and Use Committee of Institute of Animal Science and Veterinary Medicine, Shandong Academy of Agricultural Sciences. We obtained written agreements from the pig owners to use the samples.

\section{Competing interests}

The authors declare that they have no competing interests.

\section{Publisher's Note}

Springer Nature remains neutral with regard to jurisdictional claims in published maps and institutional affiliations.

\section{Author details}

${ }^{1}$ Key Laboratory of Animal Genetics, Breeding and Reproduction, Ministry of Agriculture, College of Animal Science and Technology, China Agricultural University, Beijing 100193, China. ${ }^{2}$ Shandong Provincial Key Laboratory of Animal Disease Control and Breeding, Institute of Animal Science and Veterinary Medicine, Shandong Academy of Agricultural Sciences, Jinan 250100, China.

Received: 19 July 2017 Accepted: 30 April 2018

Published online: 18 May 2018

\section{References}

1. Rubin CJ, Megens HJ, Barrio AM, Maqbool K, Sayyab S, Schwochow D, Wang C, Carlborg Ö, Jern P, Jørgensen C, et al. Strong signatures of selection in the domestic pig genome. Proc Natl Acad Sci U S A. 2012; 109(48):19529-36.

2. Wilkinson S, Lu ZH, Megens HJ, Archibald AL, Haley C, Jackson IJ, Groenen MA, Crooijmans RP, Ogden R, Wiener P. Signatures of diversifying selection in European pig breeds. PLoS Genet. 2013;9(4):e1003453.

3. Wright SS. The genetical structure of populations. Ann Eugenics. 1951;15(4):323-54.

4. Sabeti PC, Reich DE, Higgins JM, Levine HZP, Richter DJ, Schaffner SF, Gabriel SB, Platko JV, Patterson NJ, McDonald GJ. Detecting recent positive selection in the human genome from haplotype structure. Nature. 2002; 419(6909):832-7.

5. Voight BF, Kudaravalli S, Wen X, Pritchard JK. A map of recent positive selection in the human genome. PLoS Biol. 2006;4(3):e72.

6. Nielsen R, Williamson S, Kim Y, Hubisz MJ, Clark AG, Bustamante C. Genomic scans for selective sweeps using SNP data. Genome Res. 2005;15(11):1566-75.

7. Chen M, Pan D, Ren H, Fu J, Li J, Su G, Wang A, Jiang L, Zhang Q, Liu $J F$. Identification of selective sweeps reveals divergent selection between Chinese Holstein and Simmental cattle populations. Genet Sel Evol. 2016;48(1):76

8. Yang S, Li X, Li K, Fan B, Tang Z. A genome-wide scan for signatures of selection in Chinese indigenous and commercial pig breeds. BMC genet. 2014;15(1):7.

9. Li Y, Reynolds A, Boyko AR, Wayne RK, Wu D-D, Zhang Y-P. Artificial selection on brain-expressed genes during the domestication of dog. Mol Biol Evol. 2013:30(8):1867-76.

10. Vitti JJ, Grossman SR, Sabeti PC. Detecting natural selection in genomic data. Annu Rev Genet. 2013:47:97-120.

11. Grossman SR, Shlyakhter I, Karlsson EK, Byrne EH, Morales S, Frieden G, Hostetter E, Angelino E, Garber M, Zuk O, et al. A composite of multiple signals distinguishes causal variants in regions of positive selection. Science. 2010;327(5967):883-6.

12. Chen Q-M, Wang H, Zeng Y-Q, Chen W. Developmental changes and effect on intramuscular fat content of H-FABP and A-FABP mRNA expression in pigs. J Appl appl Genet. 2013;54(1):119-23.

13. Lu P, Li D, Yin J, Zhang L, Wang Z. Flavour differences of cooked longissimus muscle from Chinese indigenous pig breeds and hybrid pig breed (Duroc landrace large white). Food Chem. 2008;107(4):1529-37.

14. Chen W, Fang G, Wang S, Wang H, Zeng Y. Longissimus lumborum muscle transcriptome analysis of Laiwu and Yorkshire pigs differing in intramuscular fat content. Genes Genom. 2017;39:759-66.

15. Purcell S, Neale B, Todd-Brown K, Thomas L, Ferreira MA, Bender D, Maller J, Sklar P, de Bakker PI, Daly MJ, et al. PLINK: a tool set for whole-genome association and population-based linkage analyses. Am J Hum Genet. 2007; 81(3):559-75.

16. Groenen MA, Archibald AL, Uenishi H, Tuggle CK, Takeuchi Y, Rothschild MF, Rogel-Gaillard C, Park C, Milan D, Megens HJ, et al. Analyses of pig genomes provide insight into porcine demography and evolution. Nature. 2012; 491(7424):393-8.

17. Yang J, Lee SH, Goddard ME, Visscher PM. GCTA: a tool for genome-wide complex trait analysis. Am J Hum Genet. 2011;88(1):76-82. 
18. Yang J, Benyamin B, McEvoy BP, Gordon S, Henders AK, Nyholt DR, Madden PA Heath AC, Martin NG, Montgomery GW, et al. Common SNPs explain a large proportion of the heritability for human height. Nat Genet. 2010;42(7):565-9.

19. Gianola D, Simianer H, Qanbari S. A two-step method for detecting selection signatures using genetic markers. Genet Res. 2010;92(2):141-55.

20. Bianco E, Nevado B, Ramos-Onsins SE, Perez-Enciso M. A deep catalog of autosomal single nucleotide variation in the pig. PLoS One. 2015; 10(3):e0118867.

21. Browning SR, Browning BL. Rapid and accurate haplotype phasing and missing-data inference for whole-genome association studies by use of localized haplotype clustering. Am J Hum Genet. 2007;81(5):1084-97.

22. Fay JC, Wu Cl. Hitchhiking under positive Darwinian selection. Genetics. 2000;155(3):1405-13

23. Kim Y, Stephan W. Detecting a local signature of genetic hitchhiking along a recombining chromosome. Genetics. 2002;160(2):765-77.

24. DeGiorgio M, Huber CD, Hubisz MJ, Hellmann I, Nielsen R. SweepFinder2: increased sensitivity, robustness and flexibility. Bioinformatics. 2016;32(12):1895-7.

25. Pickrell JK, Coop G, Novembre J, Kudaravalli S, Li JZ, Absher D, Srinivasan BS, Barsh GS, Myers RM, Feldman MW, et al. Signals of recent positive selection in a worldwide sample of human populations. Genome Res. 2009;19(5):826-37.

26. Suzuki Y. Statistical methods for detecting natural selection from genomic data. Genes Genet Syst. 2010;85(6):359-76.

27. Oleksyk TK, Smith MW, O'Brien SJ. Genome-wide scans for footprints of natural selection. Philos Trans R Soc Lond Ser B Biol Sci. 2010;365(1537):185-205.

28. Innan $H$, Kim Y. Detecting local adaptation using the joint sampling of polymorphism data in the parental and derived populations. Genetics. 2008; 179(3):1713-20.

29. Sabeti PC, Varilly P, Fry B, Lohmueller J, Hostetter E, Cotsapas C, Xie X, Byrne EH, McCarroll SA, Gaudet R, et al. Genome-wide detection and characterization of positive selection in human populations. Nature. 2007; 449(7164):913-8.

30. Williamson SH, Hubisz MJ, Clark AG, Payseur BA, Bustamante CD, Nielsen R Localizing recent adaptive evolution in the human genome. PLoS Genet. 2007;3(6):e90.

31. Nielsen R, Hubisz MJ, Clark AG. Reconstituting the frequency spectrum of ascertained single-nucleotide polymorphism data. Genetics. 2004; 168(4):2373-82

32. Nielsen R. Population genetic analysis of ascertained SNP data. Hum Genomics. 2004;1(3):218-4.

33. Frantz LA, Schraiber JG, Madsen O, Megens HJ, Bosse M, Paudel Y, Semiadi G, Meijaard E, Li N, Crooijmans RP, et al. Genome sequencing reveals fine scale diversification and reticulation history during speciation in Sus. Genome Biol. 2013;14(9):R107.

34. Bosse M, Megens HJ, Madsen O, Frantz LA, Paudel Y, Crooijmans RP, Groenen MA. Untangling the hybrid nature of modern pig genomes: a mosaic derived from biogeographically distinct and highly divergent Sus scrofa populations. Mol Ecol. 2014;23(16):4089-102.

35. Wang C, Wang H, Zhang Y, Tang Z, Li K, Liu B. Genome-wide analysis reveals artificial selection on coat colour and reproductive traits in Chinese domestic pigs. Mol Ecol Resour. 2015;15(2):414-24.

36. Ma Y, Wei J, Zhang Q, Chen L, Wang J, Liu J, Ding X. A genome scan for selection signatures in pigs. PLoS One. 2015:10(3):e0116850.

37. Bell CG, Walley AJ, Froguel P. The genetics of human obesity. Nat Rev Genet. 2005;6(3):221-34.

38. Barsh GS, Schwartz MW. Genetic approaches to studying energy balance: perception and integration. Nat Rev Genet. 2002;3(8):589-600.

39. Inui A. Neuropeptide $Y$ feeding receptors: are multiple subtypes involved? Trends Pharmacol Sci. 1999;20(2):43-6.

40. Nguyen AD, Mitchell NF, Lin S, Macia L, Yulyaningsih E, Baldock PA, Enriquez RF, Zhang L, Shi YC, Zolotukhin S, et al. Y1 and Y5 receptors are both required for the regulation of food intake and energy homeostasis in mice. PLoS One. 2012;7(6):e40191.

41. Elbers CC, de Kovel CG, van der Schouw YT, Meijboom JR, Bauer F, Grobbee DE, Trynka G, van Vliet-Ostaptchouk JV, Wijmenga C, Onland-Moret NC. Variants in neuropeptide $Y$ receptor 1 and 5 are associated with nutrientspecific food intake and are under recent selection in Europeans. PLoS One. 2009:4(9):e7070

42. Jenkinson CP, Cray K, Walder K, Herzog H, Hanson, Ravussin E. Novel polymorphisms in the neuropeptide- $Y$ Y 5 receptor associated with obesity in pima Indians. Int J Obes Relat Metab Disord. 2000;24(5):580-4.
43. Li P, Tiwari HK, Lin WY, Allison DB, Chung WK, Leibel RL, Yi N, Liu N. Genetic association analysis of 30 genes related to obesity in a European American population. Int J Obes. 2014;38(5):724-9.

44. Li M, Chen L, Tian S, Lin Y, Tang Q, Zhou X, Li D, Yeung CK, Che T, Jin L, et al. Comprehensive variation discovery and recovery of missing sequence in the pig genome using multiple de novo assemblies. Genome Res. 2016;27:865-74.

45. Sohn JW, Elmquist JK, Williams KW. Neuronal circuits that regulate feeding behavior and metabolism. Trends Neurosci. 2013;36(9):504-12.

46. Hill JW, Williams KW, Ye C, Luo J, Balthasar N, Coppari R, Cowley MA, Cantley LC, Lowell BB, Elmquist JK. Acute effects of leptin require PI3K signaling in hypothalamic proopiomelanocortin neurons in mice. J Clin Invest. 2008;118(5):1796-805.

47. Kadowaki T, Tobe K, Honda-Yamamoto R, Tamemoto H, Kaburagi $Y$, Momomura K, Ueki K, Takahashi Y, Yamauchi T, Akanuma Y, et al. Signal transduction mechanism of insulin and insulin-like growth factor-1. Endocr J. 1996;43(Suppl):S33-41.

48. Terauchi Y, Tsuji Y, Satoh S, Minoura H, Murakami K, Okuno A, Inukai K, Asano T, Kaburagi Y, Ueki K, et al. Increased insulin sensitivity and hypoglycaemia in mice lacking the p85 alpha subunit of phosphoinositide 3-kinase. Nat Genet. 1999;21(2):230-5.

49. Couve A, Restituito S, Brandon JM, Charles KJ, Bawagan H, Freeman KB, Pangalos MN, Calver AR, Moss SJ. Marlin-1, a novel RNA-binding protein associates with GABA receptors. J Biol Chem. 2004;279(14):13934-43.

50. Xu Z, Ji C, Zhang Y, Zhang Z, Nie Q, Xu J, Zhang D, Zhang X. Combination analysis of genome-wide association and transcriptome sequencing of residual feed intake in quality chickens. BMC Genomics. 2016:17:594

51. Munoz G, Ovilo C, Estelle J, Silio L, Fernandez A, Rodriguez C. Association with litter size of new polymorphisms on ESR1 and ESR2 genes in a Chinese-European pig line. Genet Sel Evol. 2007;39(2):195-206.

52. van Rens BTTM, de Groot PN, van der Lende T. The effect of estrogen receptor genotype on litter size and placental traits at term in F2 crossbred gilts. Theriogenology. 2002;57(6):1635-49.

53. Rothschild M, Jacobson C, Vaske D, Tuggle C, Wang LZ, Short T, Eckardt G, Sasaki S, Vincent A, McLaren D, et al. The estrogen receptor locus is associated with a major gene influencing litter size in pigs. Proc Natl Acad Sci U S A. 1996;93(1):201-5.

54. Wysolmerski JJ, Philbrick WM, Dunbar ME, Lanske B, Kronenberg H, Karaplis A, Broadus AE. Rescue of the parathyroid hormone-related protein knockout mouse demonstrates that parathyroid hormone-related protein is essential for mammary gland development. Development. 1998;125(7):1285-94.

55. Kobayashi T, Kronenberg HM, Foley J. Reduced expression of the PTH/PTHrP receptor during development of the mammary gland influences the function of the nipple during lactation. Dev Dyn. 2005;233(3):794-803.

56. Tetzlaff S, Chomdej S, Jonas E, Ponsuksili S, Murani E, Phatsara C, Schellander K, Wimmers K. Association of parathyroid hormone-like hormone (PTHLH) and its receptor (PTHR1) with the number of functional and inverted teats in pigs. J Anim Breed Genet. 2009;126(3):237-41.

\section{Ready to submit your research? Choose BMC and benefit from:}

- fast, convenient online submission

- thorough peer review by experienced researchers in your field

- rapid publication on acceptance

- support for research data, including large and complex data types

- gold Open Access which fosters wider collaboration and increased citations

- maximum visibility for your research: over $100 \mathrm{M}$ website views per year

At BMC, research is always in progress.

Learn more biomedcentral.com/submissions 